\title{
Inactivation of Protein Tyrosine Phosphatase 1B (PTP1B) Activity by the Aqueous Partition of Guava Leaf Extract
}

Wan-Jung $\mathrm{Wu}^{1}$, Wei-Li $\mathrm{Yan}^{1}$, Shiou-Cherng $\mathrm{Yu}^{1}$, Gerry Gunawan ${ }^{1}$, Chien-Yih $\mathrm{Lin}^{1}$, Chih-Yan Huang ${ }^{1}$, Chia-Ting Chang ${ }^{2}$, Haw-Wen Chen ${ }^{2}$, Chong-Kuei Lii ${ }^{2}$, Alice L. $\mathrm{Yu}^{3}$, Ching-Chu Chen ${ }^{4}{ }^{5}$, Yu-Ting Chung ${ }^{6}$ Jeng-Dau Tsai ${ }^{7,8}$ and Henry J. Tsai ${ }^{9}$

1. Department of Biotechnology, Asia University, 500, Lioufeng Rd. Wufeng District, Taichung 413, Taiwan

2. Department of Nutrition, China Medical University, 91 Hsueh-Shih Rd, Taichung 404, Taiwan

3. Genomics Research Center, Academia Sinica, 128, Section 2 of Academia Rd, Nankang District, Taipei 115, Taiwan

4. Division of Endocrinology and Metabolism, Department of Medicine, China Medical University Hospital, Taichung, Taiwan

5. School of Chinese Medicine, China Medical University, Taichung, Taiwan

6. Asia University Hospital, Wufeng, Taichung

7. College of Medicine, Chung Shan Medical University, 110, Section 1 of Jianguo North Rd, Taichung 402, Taiwan

8. Department of Pediatrics, Chung Shan Medical University Hospital, 110, Section 1 of Jianguo North Rd, Taichung 402, Taiwan

9. Department of Health and Nutrition, Asia University, 500, Lioufeng Rd. Wufeng District, Taichung 413, Taiwan

\begin{abstract}
Guava leaf tea has been used as a folk medicine for treating hyperglycemic conditions in Asia and Africa. The hypoglycemic efficacy of guava leaf has been documented by many scientists in these regions, but the hypoglycemic mechanism is poorly understood. Guava leaves were extracted with methanol and the crude extract was partitioned against hexane, ethyl acetate, and butanol in sequence. The leftover in water is defined as the aqueous partition. A second smaller batch was extracted with hot water directly. Oral glucose tolerance test was carried out on healthy mice instead of diabetic mice that lack endogenous insulin. Glucose uptake was examined with 3T3-L1 adipocytes. Oxidative effect on PTP1B (protein tyrosine phosphatase 1b) was carried out with real-time PTP1B enzymatic assay. The aqueous partition of guava leaf extract possesses a potent inhibitory effect on PTP1B enzymatic activity and this PTP1B inhibition is through a slow oxidative but reversible inactivation on the enzyme. The reversible inactivation would suggest guava leaf extract may augment PTP1B inhibition alongside the endogenous $\mathrm{H}_{2} \mathrm{O}_{2}$ which itself is induced by insulin. In addition, our study confirmed the hypoglycemic efficacy being associated with guava leaf and found the most effective molecules reside in the aqueous partition which is also less cytotoxic to Chinese hamster ovary cells when compared to other less polar partitions. The guava leaf extract can modulate insulin activity through a redox regulation on PP1B enzymatic activity. It is speculated that a compound similar to gallocatechin in the aqueous partition can reduce an oxygen molecule to hydrogen peroxide which in turn oxidizes the catalytic residue Cys in PTP1B. Therefore, the guava leaf tea can serve as a functional hypoglycemic drink that is suitable for either healthy or diabetic subjects.
\end{abstract}

Key words: Guava leaf extract, hypoglycemic, oxidative, protein tyrosine phosphatase 1b, slow inactivation.

\begin{tabular}{llll}
\multicolumn{2}{l}{ Abbreviations } & DTT & Dithiothreitol \\
$\mathrm{Aq}$ & Aqueous partition & EA & Ethyl acetate partition \\
$\mathrm{Bu}$ & Butanol partition & EC $_{50}$ & $50 \%$ effective concentration \\
$\mathrm{BW}$ & Body weight & EGCG & Epigallocatchin gallate \\
$\mathrm{CHO}$ & Chinese hamster ovary & ESI & Electrospray ionization \\
$\mathrm{DPPH}$ & 1,1-diphenyl-2-picrylhydrazyl (radical) & FBS & Fetal bovine serum \\
& Glut-4 & Glucose transporter-4 \\
\multicolumn{2}{r}{$\begin{array}{l}\text { Corresponding author: Henry J. Tsai, Ph.D., associate } \\
\text { professor, research fields: biochemistry. }\end{array}$} & HW & Hot water extract \\
\end{tabular}




$\begin{array}{ll}\text { MTT } & \begin{array}{l}\text { 3-(4,5-dimethylthiazol-2-yl)-2,5-diphenyl } \\ \text { tetrazolium }\end{array} \\ \text { OGTT } & \text { Oral glucose tolerance test } \\ \text { PI3K } & \text { Phosphoinositide 3-kinase } \\ \text { PKB/Akt } & \text { Protein kinase B }\end{array}$

\section{Introduction}

The prevalence of diabetes mellitus is a growing concern not only in modernized Western countries, but also in other arising countries. It has been reported by Ezzati et al. [1] that the adult diabetes has quadrupled worldwide between 1980 and 2014, and the rate of diabetes has rose significantly in many countries with middle or lower incomes, such as China, Egypt, India, Indonesia, Mexico and Pakistan [1]. Diabetes mellitus is a chronic disease characteristic of a poor homeostasis of blood glucose [2]. While type 1 diabetes mellitus is a major histocompatibility complex associated autoimmune disease [3] and accounted for about 10\% of all diabetes cases; type 2 diabetes makes up approximately $90 \%$ of the cases and is frequently accompanied by obesity with insulin resistance as a preceding symptom [4].

Guava (Psidium guajava) is a tropical shrub in the Myrtle family (Myrtaceae) that is native to central and northern South America but has been cultivated worldwide. High content of flavonoids and polyphenols makes guava fruits rich in antioxidants [5]. Guava leaves have been described by folk medicines as a hypoglycemic agent in Asia [6, 7] and Africa [8], so they have long been used for treating hyperglycemic conditions in these regions. Studies by Mukhtar et al. [6], Ojewole [8], and Shen et al. [7] have confirmed the acute hypoglycemic potency being associated with the guava leaf extract on rodents, while Deguchi and Miyazaki [9] reported a similar effect on human subjects.

However, there has been no consensus on the hypoglycemic mechanism of the guava leaf extract (Table 1). Deguchi and Miyazaki [9] suggested the guava leaf water extract may inhibit digestive $\alpha$-glucosidase activities while Oh et al. [10] reported the butanol partition of guava leaf extract is capable of inhibiting PTP1B (protein tyrosine phosphatase 1b) enzymatic activity. Shen et al. [7] reported that a long term feeding of guava leaf water extract can increase plasma insulin and metabolic enzyme activities, e.g., higher hexokinase, phosphofructokinase and glucose 6-phosphate dehydrogenase enzymatic activities. Guo et al. [11] reported $70 \%$ ethanol extract can activate insulin signal molecules, e.g., IRS-1 (insulin receptor substrate-1), PKB/Akt (protein kinase B), PI3K (phosphoinositide 3-kinase) along with more membrane translocation of Glut-4 (glucose transporter-4).

Of all those possible hypoglycemic mechanisms, an inhibition on PTP1B is particularly interesting, because PTP1B is a negative regulator in the insulin signal pathway, an inhibition on PTP1B would explain many of aforementioned hypoglycemic effects associated with lowering blood glucose, in addition PTP1B is not only pivotal to insulin signal pathway, but also play a significant role in leptin signal pathway which regulates appetite. Since type 2 diabetes is frequently associated with obesity, a reduction in body

Table 1 Summary of published experiments pertinent to acute hypoglycemic effect of guava leaf extract.

\begin{tabular}{llllll}
\hline Author (s) & Year & Fraction & Subjects & Methods, dose & Latency \\
\hline Mukhtar et al. & 2004 & Water & Wistar & OGTT, 250 mg/kg & $1 \mathrm{~h}$ \\
Ojewole & 2005 & Water & Wistar & OGTT, 200 mg/kg & $1-2 \mathrm{~h}$ \\
Oh et al. & 2005 & Butanol & $d b / d b^{\mathrm{a}}$ & i.p. $10 \mathrm{mg} / \mathrm{kg}$ & $4 \mathrm{wk}$ \\
Shen et al. & 2008 & Water & Sprague-D & OGTT, 200 mg/kg & $30 \mathrm{~min}$ \\
Cheng et al. & 2009 & Water & Heptocytes & Glucose uptake & $30 \mathrm{~min}$ \\
Deguchi \& Miyazaki & 2010 & Water & Human & CHO load, 250 mg/kg & $30 \mathrm{~min}$ \\
Guo et al. & 2013 & Ethanol & SHRSP/ZF & OGTT & $1-2 \mathrm{~h}$ \\
\hline
\end{tabular}

a mice with recessive mutant gene on leptin receptor;

${ }^{\mathrm{b}}$ crossbreed of spontaneous hypertensive rats-stroke prone rats and Zucker fa/fa rats. 
weight/appetite would have a profound influence on type 2 diabetes.

\section{Material and Methods}

\subsection{Materials}

Guava leaves were obtained from the farmer's union at Shetou Township located in Changhua County of Midwestern Taiwan. Organic solvents were purchased from Echo Chemical Co. Taiwan. The tissue cell culture medium and serum were products of Gibco Life Technologies (Carlsbad, CA, USA). MTT, 3-(4,5-dimethylthiazol-2-yl)-2,5-diphenyl tetrazolium, was purchased from Invitrogen (Carlsbad, CA, USA). DPPH, 1,1-diphenyl-2-picrylhydrazyl (radical) was purchased from Sigma Aldrich (St Louis, MO, USA). Protein tyrosine phosphatase-1b was purchased from Calbiochem (Billerica, MA, USA). The LH-20 resin (Sephadex LH-20) was purchased from GE Healthcare (San Francisco, CA, USA). Quercetin was purchased from Sigma-Aldrich (St Louis, MO).

\subsection{Extraction and Partitioning of Guava Leaf}

Nine hundred g of dry guava (Psidium guajava) leaves were soaked in $11 \mathrm{~L}$ of methanol for one week [10]. The methanol crude extract was filtered and dried with a rotary aspirator. The crude extract was rehydrated with $10 \mathrm{x}(\mathrm{w} / \mathrm{v})$ water and partitioned subsequently with equal volume of organic solvents, hexane, ethyl acetate, and butanol, 3 times each. The final watery portion is collected as the aqueous partition. Each partition of the guava leaf extract was dried with a rotary aspirator. For the hot water extract, $300 \mathrm{~g}$ of dry guava leaves was boiled in $1 \mathrm{~L}$ deionized water for 5 minutes and repeated for 3 times before the extract (guava leaf decoction) being dried with a rotary aspirator.

\subsection{Redissolving Guava Leaf Extracts}

The dry residue of each partition was redissolved in $50 \%$ DMSO (dimethyl sulfoxide) at $0.1 \mathrm{~g} / \mathrm{mL}$ concentration, except for the aqueous partition and the hot water extract which were redissolved in deionized water directly. The DMSO in those redissolved partitions was diluted to a concentration that it has no observable impact on CHO cell viability or PTP1B enzymatic activity.

\subsection{Phenolic Content}

The phenolic content was determined by Folin-Ciocalteu method, similar to the method described by Chandra et al. 2014 [12]. Briefly, $10 \mu \mathrm{L}$ of samples containing approximately $300 \mu \mathrm{g}$ of each fraction was mixed with $80 \mu \mathrm{L}$ of $7.5 \%$ sodium biscarbonate and $10 \mu \mathrm{L}$ of Folin-Ciocalteu phenol reagent. After 30 minutes reaction at $37{ }^{\circ} \mathrm{C}$ and 5 minutes at room temperature cooling down, the purplish compound was measured by absorbance at $760 \mathrm{~nm}$. Gallic acid was used as the standard.

\subsection{Flavonoid Content}

The flavonoid content was determined by measuring their characteristic absorbance at $510 \mathrm{~nm}$ directly. Briefly, $100 \mu \mathrm{L}$ of each redissolved fraction containing approximately $300 \mu \mathrm{g}$ of sample was measured spectrophotometrically in a 96-well plate format. A solution of basic quercetin $(\mathrm{pH} 10)$ was used as the standard.

\subsection{DPPH Scavenging}

The 1, 1-diphenyl-2-picrylhydrazyl radical (DPPH) scavenging ability was measured as the concentration that causes 50\% reduction of DPPH absorbance at 517 nm, as described by Kedare and Singh 2011 [13]. Briefly, $80 \mu \mathrm{L}$ of ethanol containing various concentrations of samples $(0-160 \mu \mathrm{g})$ were added with $24 \mu \mathrm{g}$ of DPPH dissolved in $20 \mu \mathrm{L}$ of ethanol (the final concentration is $0.61 \mathrm{mM}$ DPPH). After 30 minutes incubation at room temperature, the absorbance was measured at $517 \mathrm{~nm}$ with a 96-well spectrophotometer. Most samples caused a complete reduction of DPPH absorbance with 50-200 $\mu \mathrm{g} / \mathrm{mg}$ concentrations. 


\subsection{Cytotoxicity Test}

For cytotoxicity on CHO (Chinese hamster ovary) cells, the assay was conducted based on the method described in Ref. [14]. Briefly, approximately 7,000 CHO cells were seeded in each well (of a 96-well culture plate) and incubated with $100 \mu \mathrm{L}$ D-MEM/F12 medium containing $10 \%$ FBS overnight before being added with $10 \mu \mathrm{L}$ of the serially diluted guava leaf partition or extract. The cells were further cultured 24 hours before the added partition/extract along with the medium were aspirated. The culture was washed 3 times with PBS (phosphate buffered saline) solution before $100 \mu \mathrm{L}$ D-MEM/F-12 medium and $20 \mu \mathrm{L}$ of MTT $(20 \mu \mathrm{g} / \mathrm{mL})$ was added to each well before an overnight incubation. The yellow MTT turned purple as it was chemically reduced to formazan and formed insoluble crystal at the bottom of each well. The medium containing MTT was discarded and the purple formazan crystals were dissolved with $200 \mu \mathrm{L}$ acidic isopropanol overnight. The cell viability is proportional to the formation of purple formazan which can be measured with a spectrophotometer tuned to 570 nm wavelength absorption.

\subsection{Glucose Uptake Assay}

The differentiation of 3T3-L1 preadipocytes was induced by incubation with D-MEM medium with 5\% FBS (fetal bovine serum) in the presence of $0.25 \mu \mathrm{M}$ dexamethasone, $0.5 \mathrm{mM}$ 3-isbutyl-1-methylxanthine (IBMX), and $0.17 \mu \mathrm{M}$ insulin for 4 days, followed by further incubation with D-MEM/FBS containing 0.17 $\mu \mathrm{M}$ insulin alone for 4 days, as described by Vishwanath et al. 2013 [15]. Prior to the assay, cells were deprived of insulin by incubating in D-MEM medium containing no FBS for 2 hours. 2-deoxy7-nitrobenzoxadiazol amino-D-glucose (NBD-glucose) was used as the tracer which can be detected with $465 \mathrm{~nm}$ excitation/540 nm emission fluorescence. Treatment and the tracer glucose were applied to the cells simultaneously for one hour before extracellular tracer being washed away. The intracellular tracer was mixed with scintillation fluid before being counted.

\subsection{Oral Glucose Tolerance Test}

Female balb/c mice of approximately 5 week old were purchased from National Laboratory Animal Center in Taiwan. The mice were housed in one of the animal housing facilities at Academia Sinica. The housing and handling procedures conform to the experimental animal guideline established by the Ministry of Science and Technology. Prior to the OGTT (oral glucose tolerance test), mice were deprived of rodent chow diet for at least 6 hours. Mice were body weighed to assure minimum body weight differential among experimental groups. The experiment was started by gavaging mice with $2 \mathrm{~g}$ glucose/kg body weight with or without guava leaf extract or partition. Doses used in this study are expressed as mg per $\mathrm{kg}$ of body weight (mg/kg BW). Partitions residue with poor water solubility was suspended in the glucose solution by sonication for 30 minutes. Blood samples were taken from the tail vein and blood glucose was measured with Accu-Chek glucose meters manufactured by Roche (Mannheim, Germany).

\subsection{Protein Tyrosine Phosphatase 1B Assay}

Approximately $25 \mathrm{ng}$ of PTP1B was used in each enzymatic assay. The final volume is $100 \mu \mathrm{L}$ in an opaque 96-well plate containing $50 \mathrm{mM}$ HEPES, $\mathrm{pH}$ 7.2, 1 mM DTT, 1 mM EDTA, $100 \mathrm{mM} \mathrm{NaCl}, 0.01 \%$ Triton X-100, and $15 \mu \mathrm{M}$ fluorescent substrate (difluoromethyl umbelliferyl phosphate), $K_{m}$ of which is approximately $15-20 \mu \mathrm{M} \quad$ [16]. For $\mathrm{IC}_{50}$ determination, the assay was carried out with 6 or more different concentrations of extract or partitions that encompass each prospective $\mathrm{IC}_{50}$ value. For slow inactivation of PTP1B assay, the enzyme assay mix was constituted in the absence of fluorescent substrate but with the presence of guava leaf extract. After the desired duration of incubation at room temperature, the 
substrate was added to start measuring the remaining PTP1B enzymatic activity.

\subsection{Liquid Chromatography-Mass Spectrometry (LC-MS)}

An Agilent 1100 series liquid chromatography system (Agilent, Waldbronn, Germany) coupled with a DAD (diode-array detector) and a Thermo Finnigan LCQ Advantage ion-trap mass spectrometer (San Jose, CA, USA) was employed for the molecular mass analysis at the Metabolomics Core Facility of the Agricultural Biotechnology Research Center, Academia Sinica, Taiwan. The extracts were separated by HPLC with a reverse phase-C18 column (Phenomenex Luna $3 \mu \mathrm{m} \mathrm{C18}, 150 \mathrm{~mm} \times 2.0 \mathrm{~mm}$ ) at a flow rate of $0.2 \mathrm{~mL} / \mathrm{min}$. The mobile phase is consisted of water (mobile phase $\mathrm{A}$ ) and $\mathrm{MeOH}$ (mobile phase B). The LC gradient was $50-15 \%$ B for 30min. The sample injection volume was $10 \mu \mathrm{L}$. Eluting peaks were monitored at $280 \mathrm{~nm}$ by DAD. Both of positive and negative ion polarity modes were used for compound ionization. The MS optimized parameters in positive ion mode were as following: source voltage, $4.5 \mathrm{kV}$; sheath gas $\left(\mathrm{N}_{2}\right), 50$ arbitrary units; capillary temperature, $250{ }^{\circ} \mathrm{C}$; capillary voltage, $4 \mathrm{~V}$; tube lens offset voltage, $35 \mathrm{~V}$. In the negative ion mode, source voltage, $-4 \mathrm{kV}$; capillary voltage, $-47 \mathrm{~V}$; tube lens offset voltage, $-45 \mathrm{~V}$. For full scan MS analysis, spectra were recorded in the range of $\mathrm{m} / \mathrm{z} 100-2,000$. The HPLC-DAD-MS system was controlled by Xcalibur ${ }^{\mathrm{TM}}$ 2.0 SR2 software (Thermo Finnigan, San Jose, CA, USA).

\section{Results}

\subsection{Phytochemicals}

The total phenol, flavonoid and DPPH scavenging contents of various guava leaf extracts are listed in Table 2. The aqueous partition has the lowest contents in phenolic and DPPH scavenging, while its flavonoid content is among the lower groups along with butanol and hot water extracts. In terms of PTP1B inhibition, the aqueous partition and hot water extract are more potent with $\mathrm{IC}_{50}$ at $31-33 \mu \mathrm{g} / \mathrm{mL}$, while other fractions range from $200-1,400 \mu \mathrm{g} / \mathrm{mL}$. As CHO cytotoxicity, the aqueous partition is the least toxic with an $\mathrm{IC}_{50}$ of $2.6 \mathrm{mg} / \mathrm{mL}$, followed by hot water extract at $1.2 \mathrm{mg} / \mathrm{mL}$, as illustrated in Table 2.

\subsection{Oral Glucose Tolerance Test}

Because PTP1B is a negative regulator in the insulin signal pathway, an inhibition on PTP1B would not illustrate itself if there is no insulin to initiate the pathway. Therefore, Healthy, non-diabetic, mice were chosen for examining the potency of guava leaf extract partitions in vivo. Since an inhibition on metabolic or

Table 2 Phenolic, flavonoids, and DPPH scavenging contents; inhibition of PTP1B enzymatic activity and cytotoxicity on CHO cells associated with fractions of guava leaves.

\begin{tabular}{llllll}
\hline Solvent & Phenolic $^{\mathrm{b}}$ & Flavonoids $^{\mathrm{c}}$ & DPPH EC $_{50}{ }^{\mathrm{d}}$ & PTP1B IC $_{50}{ }^{\mathrm{e}}$ & CHO Toxicity $^{\mathrm{f}}$ \\
\hline Methanol & $331.0 \pm 7.8(3)^{\mathrm{a}}$ & $19.5 \pm 1.7(3)$ & $67.1 \pm 7.5(3)$ & $403.3 \pm 16.7(3)$ & $175.8 \pm 41.5(5)$ \\
n-Hexane & $326.5 \pm 18.1(3)$ & $31.7 \pm 5.4(3)$ & $70.3 \pm 0.5(3)$ & $1,442.0 \pm 27.1(5)$ & $102.2 \pm 24.9(5)$ \\
Ethyl acetate & $255.1 \pm 21.1(3)$ & $25.0 \pm 5.9(3)$ & $48.7 \pm 0.5(3)$ & $200.0 \pm 3.2(5)$ & $40.3 \pm 9.4(5)$ \\
Butanol & $225.5 \pm 9.1(3)$ & $6.4 \pm 2.2(3)$ & $38.5 \pm 0.3(3)$ & $194.0 \pm 5.1(5)$ & $67.6 \pm 18.2(5)$ \\
Aqueous & $137.2 \pm 19.8(3)$ & $6.9 \pm 2.1(3)$ & $124.7 \pm 1.3(3)$ & $30.7 \pm 1.8(6)$ & $2,600.2 \pm 303.2(5)$ \\
Hot water & $265.9 \pm 21.8(3)$ & $6.8 \pm 1.0(3)$ & $70.4 \pm 10.1(3)$ & $33.0 \pm 0.6(3)$ & $1,193.1 \pm 171.5(5)$ \\
\hline
\end{tabular}

\footnotetext{
${ }^{a}$ Mean \pm S.E. (replicates). Each replicate is an independent determination.

${ }^{\mathrm{b}}$ Phenolic content is expressed as equivalent of gallic acid ( $\left.\mathrm{mg} / \mathrm{g}\right)$.

${ }^{c}$ Flavonoid content is expressed as equivalent of quercetin (mg/g).

${ }^{\mathrm{d}}$ DPPH scavenging $\mathrm{EC}_{50}(\mu \mathrm{g} / \mathrm{mL})$ indicates the concentration that makes a $50 \%$ reduction of DPPH absorbance $(24 \mu \mathrm{g}$ in $100 \mu \mathrm{L}$ ethanol) at $517 \mathrm{~nm}$, see Methods for details. Higher EC $_{50}$ means less DPPH scavenging content.

${ }^{\text {e }}$ PTP1B inhibition is expressed as $\mathrm{IC}_{50}(\mu \mathrm{g} / \mathrm{mL})$ at $1 K_{m}$ of substrate.

${ }^{\mathrm{f}} \mathrm{CHO}$ cell toxicity is expressed as $\mathrm{IC}_{50}(\mu \mathrm{g} / \mathrm{mL})$ after a 24 hour exposure.
} 
signal enzyme activity is a quick but short term mechanism, we chose OGTT (oral glucose tolerance test) to examine the hypoglycemic efficacy of guava leaf extracts partitions in vivo. The OGTT results showed the aqueous partition (Aq) at $200 \mathrm{mg} / \mathrm{kg} \mathrm{BW}$ (body weight) could suppress the postprandial rise of blood glucose 30 minutes after the gavage of glucose consistently in 3 separate trials (Figs. 1A-1C); whereas hot water extract required $400 \mathrm{mg} / \mathrm{kg}$ BW to achieve a comparable effect as $200 \mathrm{mg} / \mathrm{kg}$ aqueous partition (Fig. 1C). To find out the lowest hypoglycemic threshold for the aqueous partition, 50 and $160 \mathrm{mg} / \mathrm{kg}$ BW were tested in another OGTT. It seemed 50 and $160 \mathrm{mg} / \mathrm{kg}$ BW offered similar magnitudes of postprandial glucose suppression as the $200 \mathrm{mg} / \mathrm{kg}$ did (Fig. 1D), so the hypoglycemic threshold for the aqueous partition could be $50 \mathrm{mg} / \mathrm{kg}$ BW or even lower. The hypoglycemic efficacies of other partitions were also examined with OGTT. Butanol partition at $205 \mathrm{mg} / \mathrm{kg}$ BW barely showed a minute effect, but at $300 \mathrm{mg} / \mathrm{kg} \mathrm{BW}$, it showed a hypoglycemic effect (Figs. 1E and 1F) similar to that of aqueous partition at $50-200 \mathrm{mg} / \mathrm{kg}$ BW range. For ethyl acetate partition, it did not show any hypoglycemic effect even at $350 \mathrm{mg} / \mathrm{kg} \mathrm{BW}$ (Fig. $1 \mathrm{~F})$.

\subsection{Glucose Uptake by 3T3-Adipocytes}

In order to observe the hypoglycemic effect of guava leaf extract at the cellular level, we used 3T3-adipocytes in the glucose uptake assay. We found $5 \mathrm{nM}$ of insulin induced glucose uptake by at least 1 fold $(119 \%)$ over the control group, while the aqueous partition at $0.1 \mathrm{mg} / \mathrm{mL}$ can induce just under 1 fold (85\%) over the control group. If combining $5 \mathrm{nM}$ insulin with $0.1 \mathrm{mg} / \mathrm{mL}$ aqueous partition, the induction is just slightly better than $5 \mathrm{nM}$ insulin alone (136\%), suggesting insulin and the aqueous partition have no synergistic effect, nor additive effect when stimulating glucose uptake in 3T3 adipocytes (Fig. 2A). Since it has been suggested the insulin signal is mediated through hydrogen peroxide by Goldstein et al.
[17], we investigated if the induction can be attenuated by extracellular catalase. At the presence of $0.1 \mathrm{~g} / \mathrm{L}$ of catalase, both glucose uptakes induced by the aqueous partition and by insulin with the aqueous partition reduced by approximately 14\% (Fig. 2A), suggesting that both inductions are mediated through hydrogen peroxide.

Since quercetin has been reported to be the phytochemical responsible for the hypoglycemic effect associated with guava leaf extract [7], we examined if quercetin can stimulate glucose uptake in 3T3-L1 adipocytes. At $0.01 \mathrm{mg} / \mathrm{mL}$ quercetin can stimulate glucose uptake by more than two folds ( $247 \%$, Fig. 2B), similarly to the aqueous partition, this stimulation can be attenuated by extracellular catalase $(0.1 \mathrm{mg} / \mathrm{mL})$ with a drop of $27 \%$ in glucose uptake, as illustrated in Fig. 2B.

\subsection{Two Major Species According to Mass Spectrometry}

Since the aqueous partition has the most potent hypoglycemic efficacy in OGTT and inhibitory effect on PTP1B, several attempts were made to isolate the hypoglycemic compound by screening against PTP1B inhibition assay. However, the aqueous partition has a tendency to stain LH-20 resin (i.e. reacts to the resin) and the potent PTP1B inhibitory compound yields were always low even when scaled up. From a pilot study, the most potent fraction for PTP1B inhibition has an $\mathrm{IC}_{50}$ of $1.2 \mu \mathrm{g} / \mathrm{mL}$ approximately (rough determination, data not shown), and it is comprised of two major compounds. According to mass spectrometry, one is estimated to be $482 \mathrm{~g} /$ mole based on the anion spectra $\left(\left[\mathrm{M}-\mathrm{H}^{-}\right]=481.11\right)$ and the other is $516 \mathrm{~g} /$ mole $\left(\left[\mathrm{M}+\mathrm{H}^{+}\right]=517.09\right)$, based on the cation spectra, as illustrated in Fig. 3.

\subsection{Covalent Inactivation of PTP1B}

To identify the nature how the aqueous partition inactivates PTP1B enzymatic activity, another PTP1B inhibition was carried out along with 4 other fractions, 


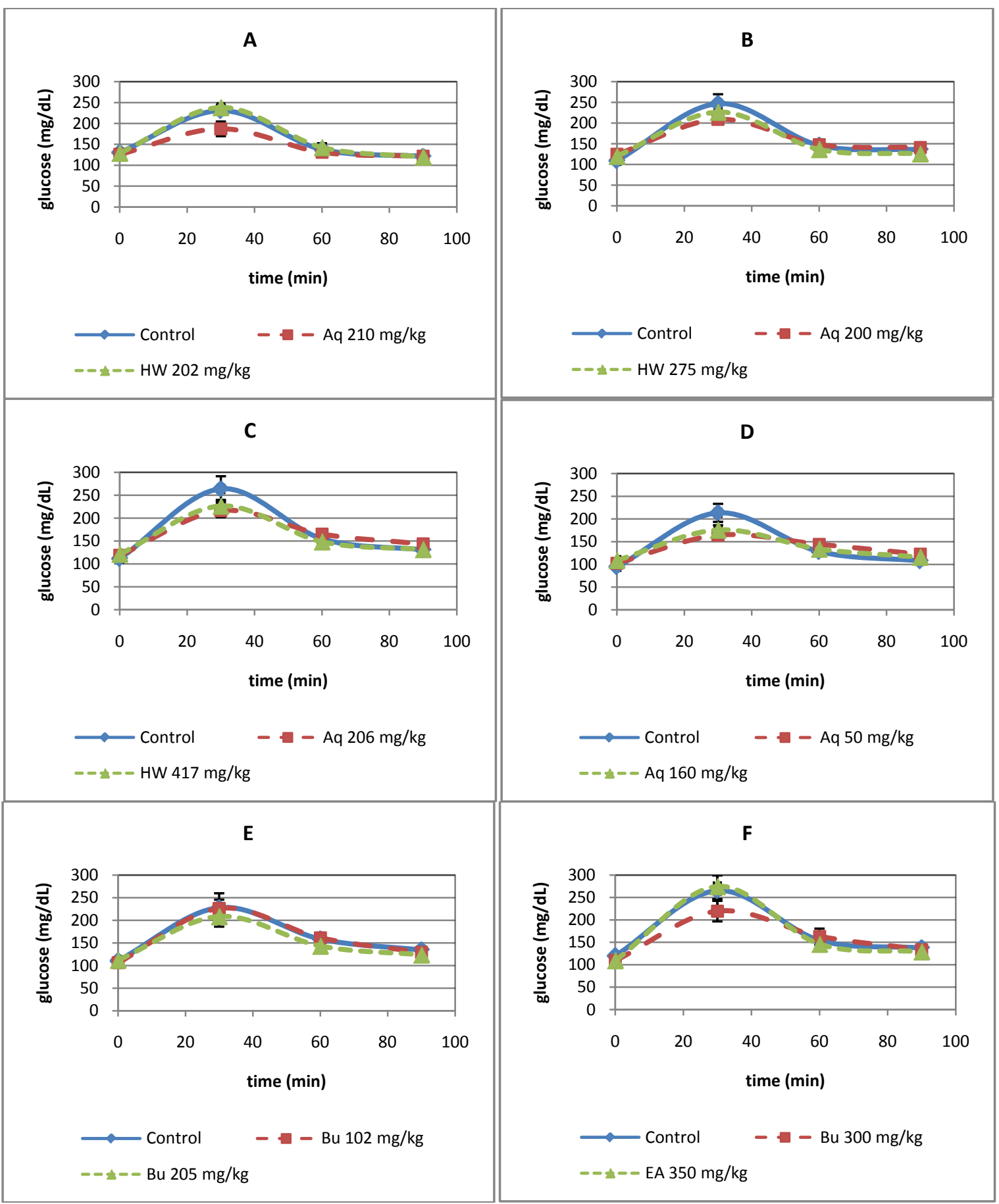

Fig. 1 OGTT (oral glucose tolerance test) on the aqueous partition, hot water extracts and other organic partitions of guava leaves. Healthy non-diabetic female balb/c mice of approximately 6 week old were used in this study. Two gram glucose per kg of body weight (BW) was gavaged alongside with the partition or extract of guava leaves. The control group received glucose alone and was tested alongside with the treatment groups. Each point is an average of $\mathbf{6}$ mice for the control group or $\mathbf{5}$ mice for the other two treatment groups and the error bars indicate standard errors. (A), (B), and (C), OGTT were carried out with increasing dose of hot water extract (HW), 202, 275, and $417 \mathrm{mg} / \mathrm{kg} \mathrm{BW}$ in comparison with the control and $200 \mathrm{mg} / \mathrm{kg} \mathrm{BW}$ aqueous partition (Aq) groups. (D), lower doses of 50 and $160 \mathrm{mg} / \mathrm{kg}$ Aq showed comparable hypoglycemic effect as those 200 mg/kg Aq groups in (A), (B) and (C). (E), butanol partition (Bu) at 205 mg/kg BW barely showed a hypoglycemic effect while $102 \mathrm{mg} / \mathrm{kg} \mathrm{BW}$ is indistinguishable from the control group. (F), Bu at $300 \mathrm{mg} / \mathrm{kg} \mathrm{BW}$, showed a clear suppression of postprandial rise of blood glucose while ethyl acetate (EA) at $350 \mathrm{mg} / \mathrm{kg} \mathrm{BW}$ showed no hypoglycemic effect. 


\section{Glucose uptake}

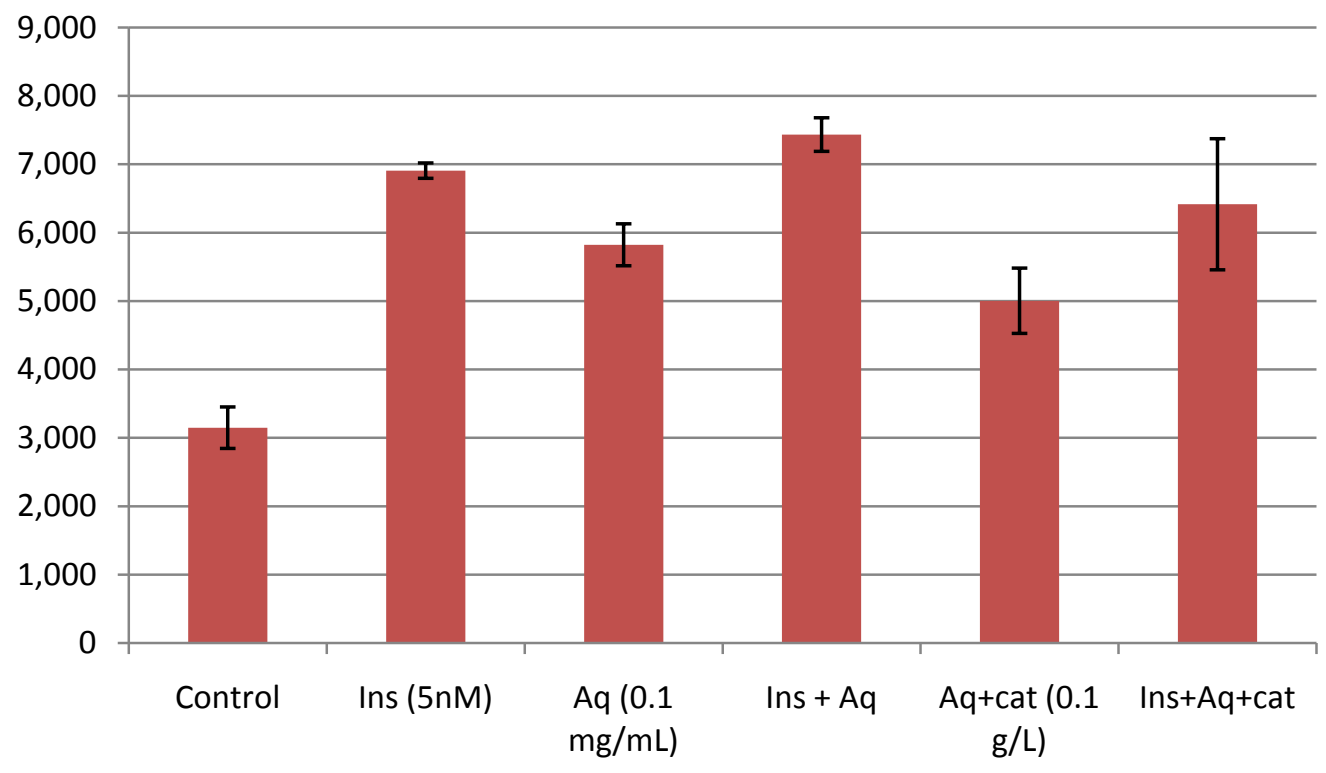

(A)

\section{T3-L1 glucose uptake}

\section{4,000}

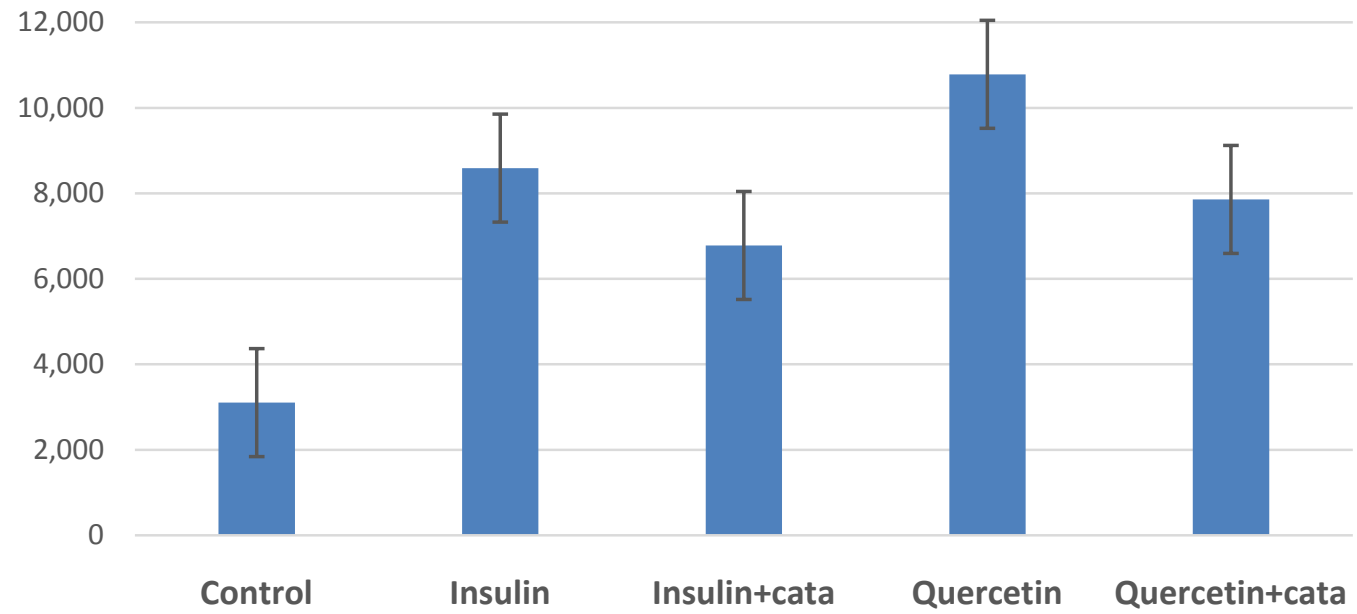

(B)

Fig. 2 Glucose uptake by differentiated 3T3-L1 adipocytes. 3T3-L1 preadipocytes were stimulated for differentiation prior to this glucose uptake assay (see Methods 2.8 for details). Treatment materials were dissolved in PBS as 10x solution, while quercetin is predissolved in DMSO before an equal volume of PBS was added to reduce DMSO concentration down to $50 \%$ and the 10x quercetin stock concentration is $0.1 \mathrm{mg} / \mathrm{mL}$ in $50 \%$ DMSO. The adipocytes were exposed to treatment and tracer glucose simultaneously for one hour before determining the uptaken glucose content (see Method 2.8 for detail). 


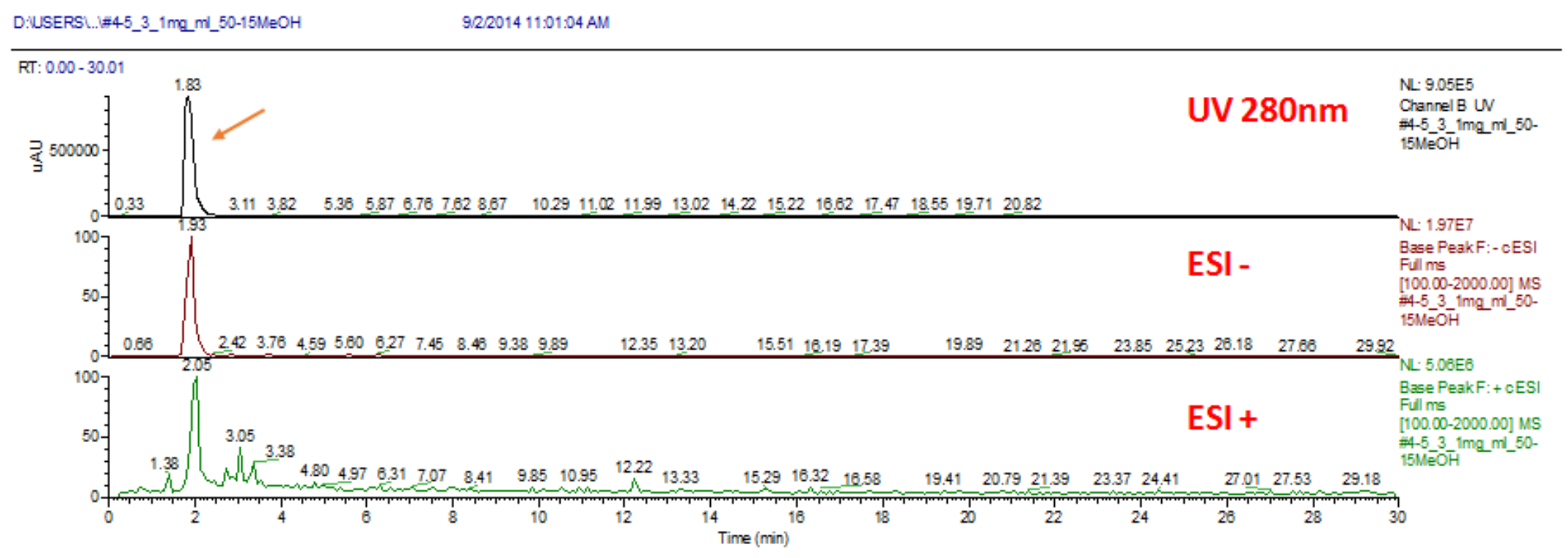




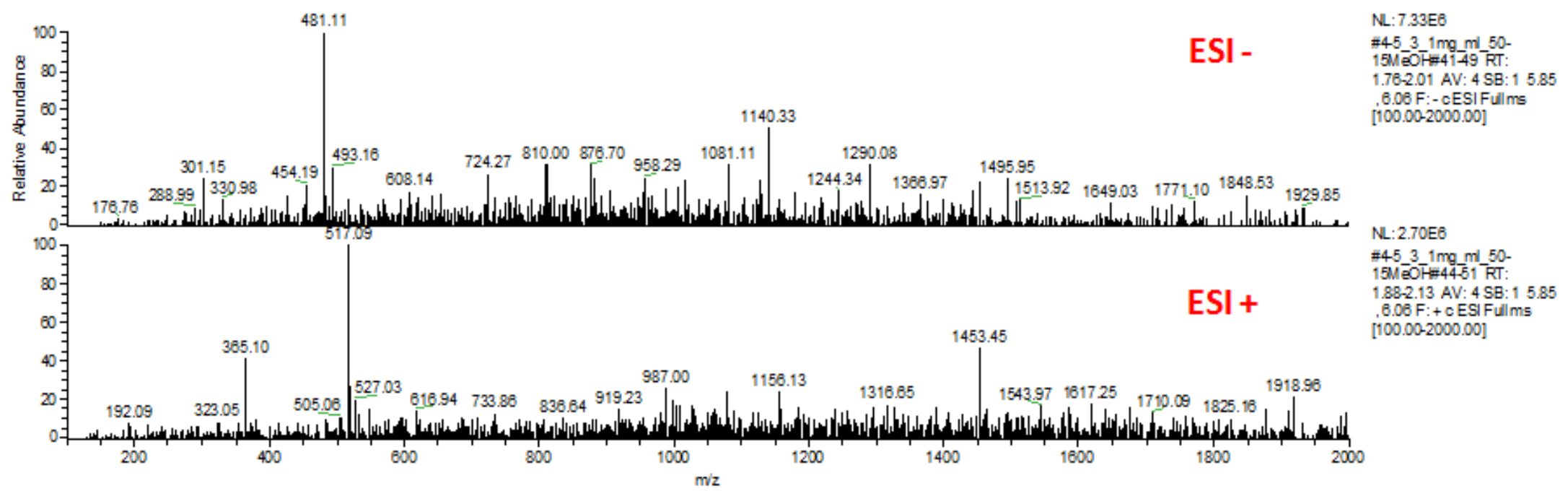

Fig. 3 Molecular weight determination by LC-MS. The most potent PTP1B inhibitory fraction isolated from an LH-20 column was analyzed for its purity and major species molecular weight. The upper panel shows the elution profile of the liquid chromatography prior to the mass spectrometry; the lower panel is the mass spectra of deprotonated anions $\left[\mathrm{M}-\mathrm{H}^{-}\right]$in ESI' and protonated cations $\left[\mathrm{M}+\mathrm{H}^{+}\right]$in $\mathrm{ESI}^{+}$. The mass spectrometry revealed a major anion species of 481.11 Da and a cation species of 517.09 Da. 
hexane, ethyl acetate, butanol partitions and the hot water extract; the result showed that the aqueous partition and the hot water extract can inactivate PTP1B slowly in a 30-minute window but the aqueous partition is more potent than the hot water extract, as shown in Fig. 4A. The inactivation power of the aqueous partition was not depleted after the first 30 minute window, since a second aliquot of PTP1B elevated the PTP1B activity but it was also inactivated in a rate similar to the first aliquot, Fig. 4B. The inactivated PTP1B can be revitalized partially by an addition of excessive Cleland's reagent $(50 \mathrm{mM}$ dithiothreitol), as shown in Fig. 4C. This result suggests the inactivation is an oxidative process, but uncertain if it is a free radical type oxidation. Preincubating the aqueous partition with a radical scavenging agent, $25.4 \mu \mathrm{M}$ DPPH, did not neutralize the oxidative potential in the aqueous partition, but the presence of DPPH actually accelerated the inactivation of PTP1B, Fig. 4D. This result is in line with the report by Kedare and Sigh that DPPH is reactive to the thiolate of protein cysteine [13]. Therefore, PTP1B oxidation by the aqueous partition is probably not a radical (single electron) type oxidation. We checked the inactivation kinetic and found the mechanism a pseudo-first order with a reaction rate of $168.17 / \mathrm{M} / \mathrm{sec}$, in Fig. 5, when assuming the aqueous partition has an average molecular weight of $499 \mathrm{~g} /$ mole, which is an average of those two major species observed from LC-MS, Fig. 3. Therefore, it is suspected that the aqueous partition might inhibit PTP1B through an oxidative inactivation probably on a cysteine residue similar to how hydrogen peroxide or isothiocyanates inhibits PTP1B enzymatic activity [18, 19], as depicted in Fig. 6.

\section{Discussion}

The hypoglycemic mechanism of guava leaf extract: the most striking part of this study is that the aqueous phase of guava leaf extract possesses an oxidative potential toward protein tyrosine phosphatase $1 \mathrm{~b}$. The phytochemicals extracted from plant leaf contains polyphenols which are generally considered antioxidants, i.e., reducing potentials not oxidative potential. However, our results have demonstrated that guava leaf extract, particularly the aqueous partition, possesses an oxidative potential toward the sulfhydryl active site on PTP1B (Fig. 4). Since this oxidative potential of guava leaf extract bears many similarities to hydrogen peroxide in the insulin signal pathway, we suggest guava leaf extract can serve as an augmentation to PTP1B regulation by hydrogen peroxide (Fig. 7).

Hypoglycemic efficacy of guava leaf extract: We have confirmed the hypoglycemic effect of guava leaf extract and the most potent fraction is the aqueous partition rather than the butanol partition as reported by Oh et al. [10]. Our initial PTP1B inhibition result would suggest that hot water extract is almost as potent as the aqueous partition ( $33 \mu \mathrm{g} / \mathrm{mL}$ vs. $31 \mu \mathrm{g} / \mathrm{mL}$, table 2 ), but the OGTT result revealed that the aqueous partition is more potent than hot water extract by at least a factor of $8(50 \mathrm{mg} / \mathrm{kg}$ vs. $400 \mathrm{mg} / \mathrm{kg})$. Therefore, the guava leaf tea or decoction may have the hypoglycemic effect, but the aqueous partition, after removal of other less polar phytochemicals, is better at preventing a postprandial rise of blood glucose. Noticeably, the hypoglycemic effect was observed on healthy non-diabetic mice, so it would suggest that the hypoglycemic efficacy of guava leaf extract being effective even on healthy subjects.

PTP1B selectivity and hypoglycemic efficacy: PTP1B inhibition has been suggested as a potential mechanism for treating diabetes since the PTP1B knock-out mice study was published [20-23]. Indeed, many pharmaceutical compounds have been synthesized with high potency, but these compounds still lack a sufficient selectivity [23] over a highly homologous isozyme, TC-PTP (T cell protein tyrosine phosphatase), which shares a very similar active site contour with PTP1B [24]. Since our aqueous partition of guava leaf extract provides a reversible (and presumably transient) oxidation on PTP1B, its selectivity 


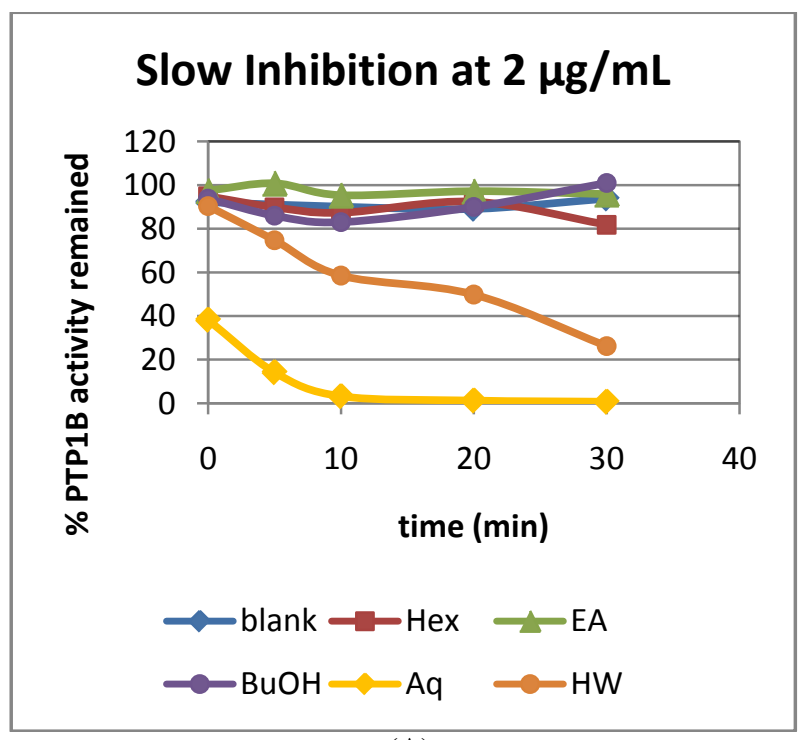

(A)

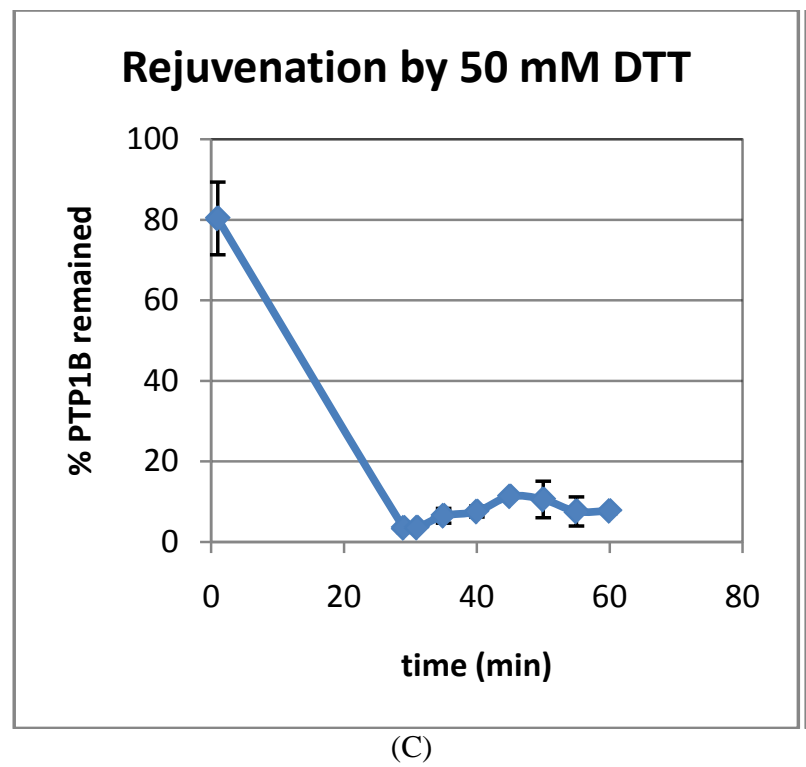

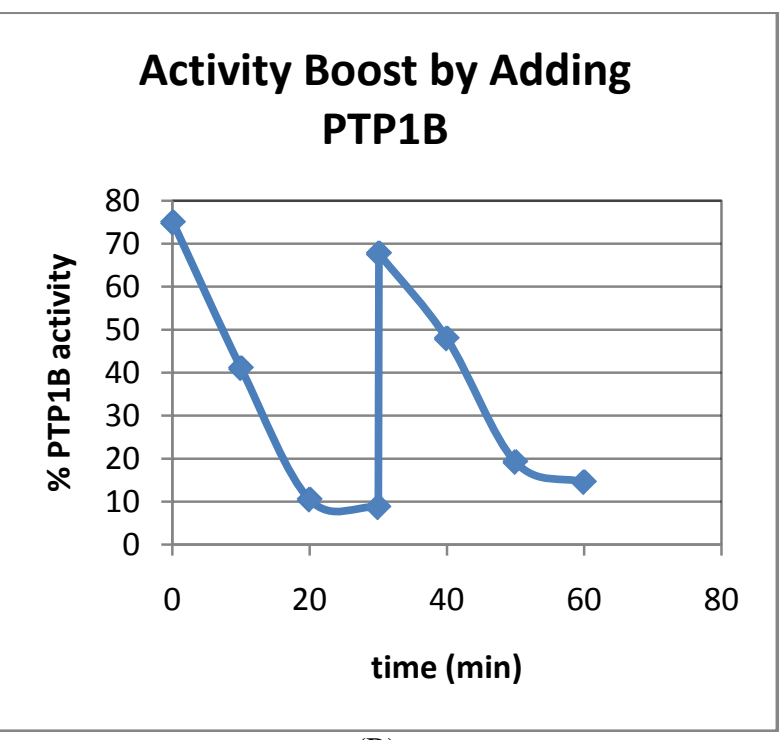

(B)

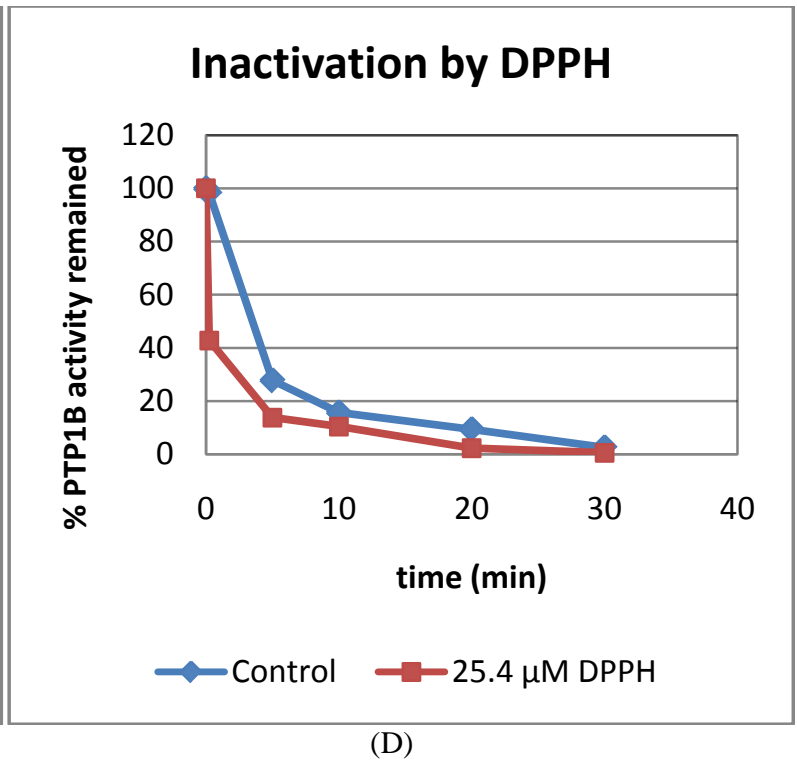

Fig. 4 Slow inactivation of protein tyrosine phosphatase $1 \mathrm{~b}$ by the aqueous partition of guava leaf extract. Single point determination unless mentioned otherwise. (A): a slow inactivation is evident when PTP1B is preincubated with $2 \mu \mathrm{g} / \mathrm{mL}$ of various partitions. Only the aqueous partition and the hot water extract have a slow inactivation of PTP1B enzyme over 30 minutes duration but the aqueous partition is more potent than the hot water extract. (B): the slow inactivation by the aqueous partition was not depleted within 30 minutes, since a second aliquot of PTP1B showed a similar inactivation rate in the next 30 minutes as the first 30 minutes. (C): the inactivated PTP1B can be revitalized partially by an addition of excess DTT after 30 min into the incubation. Each point is an average of 3 or 2 determinations; error bars indicate standard errors or half the difference. (D): the inactivation of PTP1B is not likely caused by a free radical agent in the aqueous partition, since an addition of free radical scavenger, 25.4 $\mu \mathrm{M}$ DPPH, actually accelerated the inactivation of PTP1B instead of neutralizing the oxidative agent in the aqueous partition. In fact, DPPH is able to react with the thiolate on enzymatic cysteine (13). 


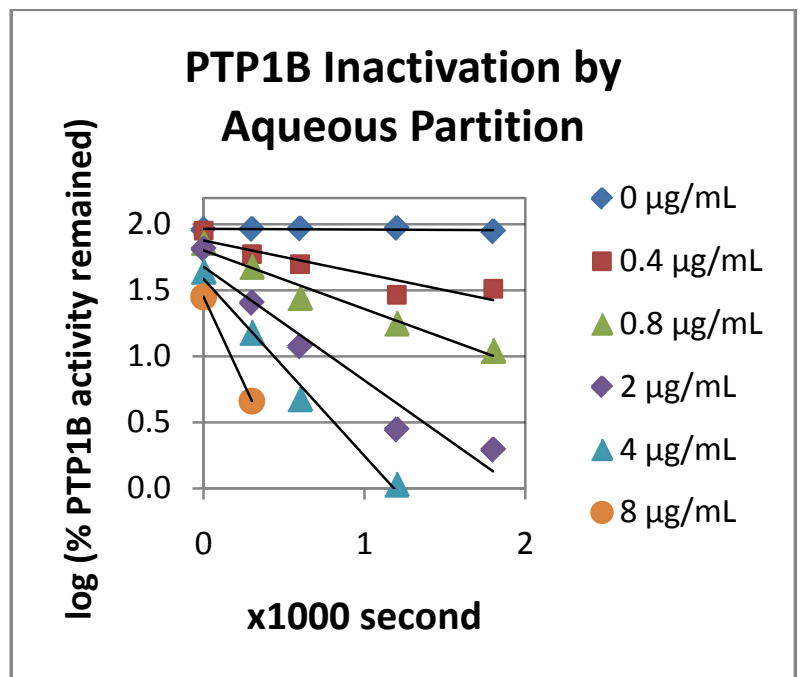

(A)

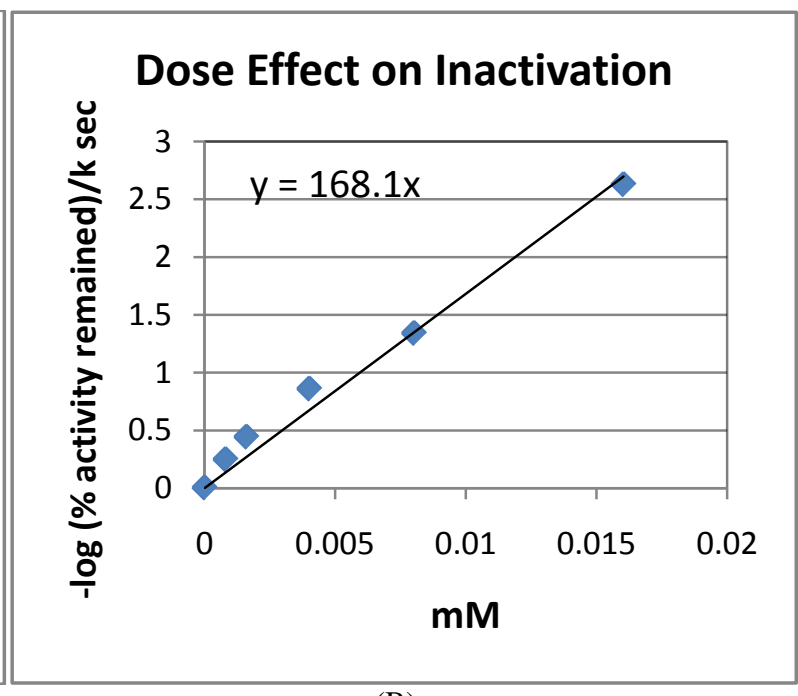

(B)

Fig. 5 (A): the slow inactivation of PTP1B by the aqueous partition (with various concentrations) showed a positive relationship between inactivation rates and extract concentrations suggesting a pseudo-first order reaction (see right panel). (B): the reaction rates is estimated to be $168.17 / \mathrm{M} / \mathrm{sec}$ by assuming the average molecular weight of the aqueous partition is 499 $\mathrm{g} / \mathrm{mole}$ (the average of 482 and $516 \mathrm{~g} / \mathrm{mole}$ from Fig. 3), the slope of the plot becomes reaction rate/M/sec.

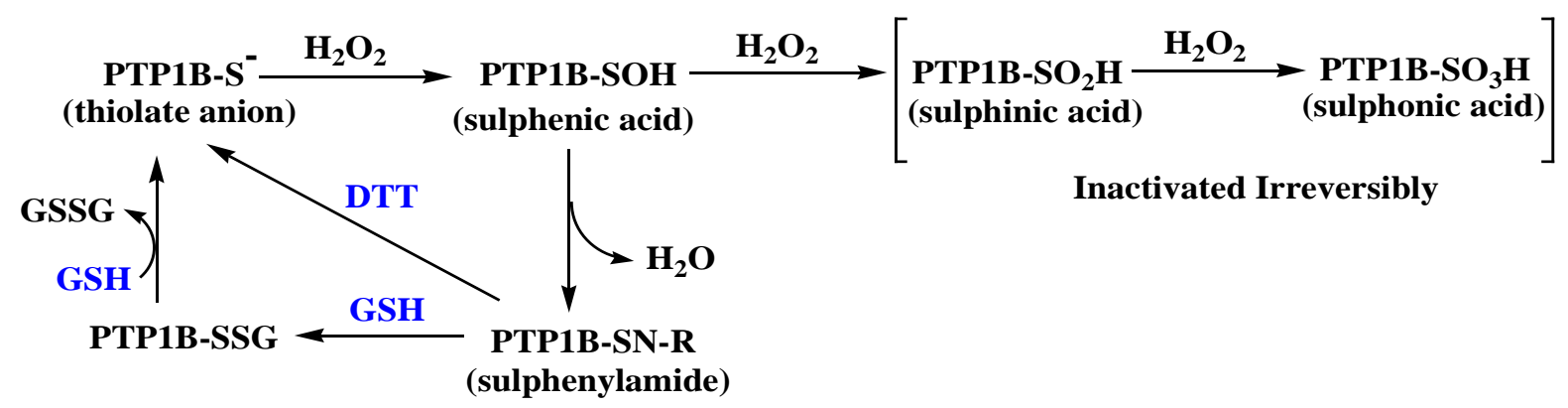<smiles>CC(C)[As]C1CSN([Pb])C1=O</smiles>

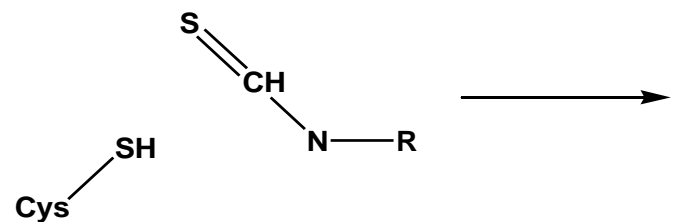<smiles>[R]NC(=S)S[AsH2]</smiles>

Fig. 6 The oxidation processes of thiolate anion on PTP1B. The hydrolysis process of protein phosphate adducts are catalyzed by the thiolate anion of cystein 215 on PTP1B. The thiolate is susceptible to hydrogen peroxide oxidation to form sulphenic acid (S-OH), the sulphenic acid can undergo a spontaneous dehydration and forms a sulphenylamide with adjacent amino group of residue 216. Either sulphenic acid or sulphenylamide can be reduced with sulfhydryl reducing agents (e.g., intracellular glutathions) or dithiothreitol (DTT) to regenerate thiolate anion, and thus PTP1B activity. However, if sulphenic acid is further oxidized by $\mathrm{H}_{2} \mathrm{O}_{2}$ to suphinic acid $\left(\mathrm{SO}_{2} \mathrm{H}\right)$ or even sulphonic acid $\left(\mathrm{SO}_{3} \mathrm{H}\right)$, they cannot be reduced by cellular sulfhydryl agent, and thus PTP1B enzymatic activity is lost irreversibly. One other covalent modification of catalytic thiolate on cysteine 215 is an incorporation of isothiocyanate to form a dithiocarbamide (19) which also renders PTP1B inactive. 


\section{Insulin}

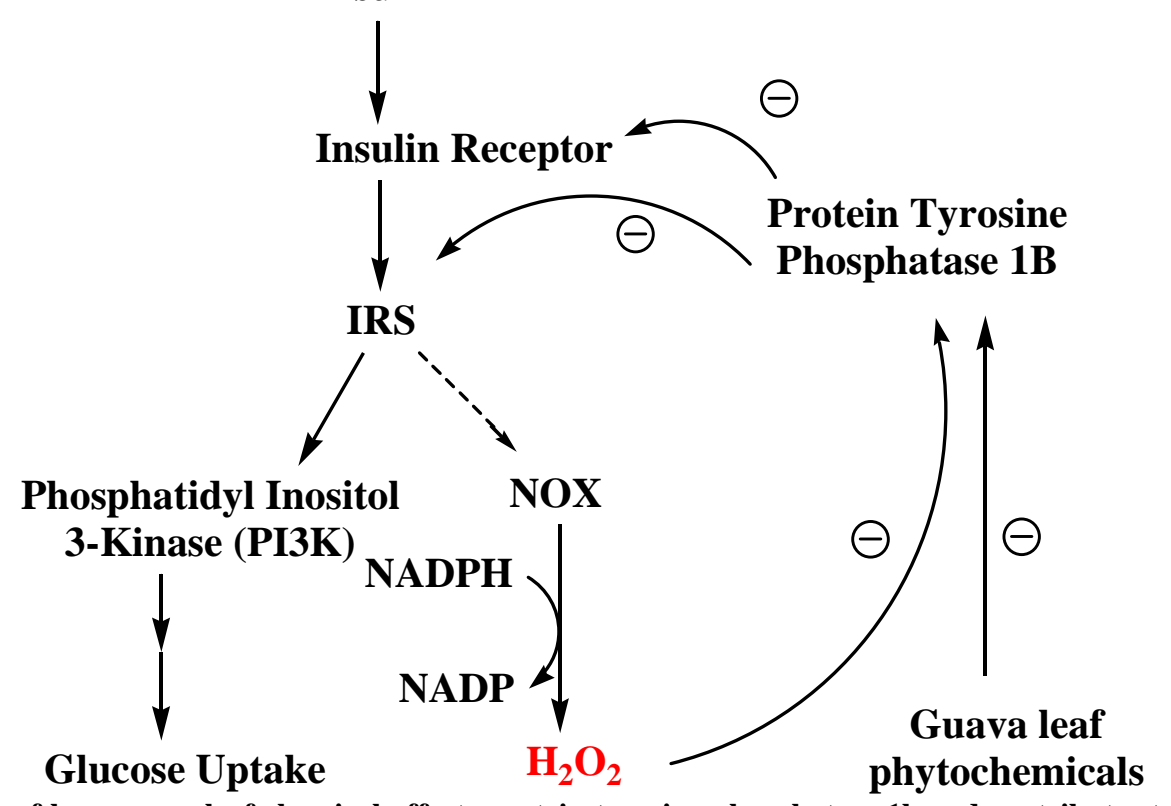

Fig. 7 Postulation of how guava leaf chemical affects protein tyrosine phosphatase $1 \mathrm{~b}$ and contributes to the hypoglycemic efficacy. Insulin activates the insulin receptor and the "insulin receptor substrate", IRS. IRS in turn activates phophatidyl insositol 3 kinase (PI3K) which leads to glucose uptake, and thus hypoglycemic efficacy. IRS can activate NADPH oxidase (NOX) 4 which generates hydrogen peroxide from oxygen with NADPH as the reducing agent. The activation of insulin receptor and IRS are subject to protein tyrosine phosphatase $1 \mathrm{~b}$ regulation, which can inactivate insulin receptor or IRS through dephosphorylation. $\mathrm{H}_{2} \mathrm{O}_{2}$ has an inhibitory effect on PTP1B through a redox affect on the catalytic Cys215 (see figure 6). Guava leaf phytochemicals have an effect on PTP1B similar to $\mathrm{H}_{2} \mathrm{O}_{2}$.

over TC-PTP is less of a concern. Therefore, we suggest that the aqueous partition can serve as a supplemental PTP1B oxidizer augmenting endogenous hydrogen peroxide induced by insulin [14, 25], as depicted in Fig. 7.

Since the guava leaf is known for its rich content of polyphenol antioxidants, it is rather baffling why the guava leaf would possess an oxidative potential that can inactivate a cysteine based enzyme. Incidentally, Nakayama et al. 2002 [26] have suggested an interesting mechanism in which a hydrogen peroxide is generated from the reduction of an oxygen molecule with two trihydroxylated phenyl rings as electron donors (antioxidants). Therefore, the antioxidant polyphenols in the tea infusion could generate hydrogen peroxide which in turn inactivates PTP1B enzymatic activity through a mild oxidation on the catalytic cysteine 215. Subsequently, Ma et al. [27] demonstrated that black tea possesses a slow PTP1B inactivation property. Given the water solubility of our guava leaf extract, the active phytocompound is very likely similar to catechin common in tea leaves. Therefore, we speculate a compound similar to EGCG (epigallocatechin gallate) could be involved in our study, but EGCG has a molecular weight of $458 \mathrm{~g} / \mathrm{mole}$, still 24 g/mole below our anion spectra peak of 482 $\mathrm{g} /$ mole. After substituting the gallate moiety with a glucose or a hexose as well as a ketone oxidation on C4 position, the molecular weight would come to 482.11 $\mathrm{g} /$ mole, an exact match to the anion peak in LC-MS, as illustrated in Fig. 3. Therefore, we speculate the phytochmical in the aqueous partition that bears PTP1B inactivation property be a gallo 4-one catechin 3-hexose (glucose) molecule as shown in Fig. 8. However, this would need further confirmation.

Our LC-MS result showed one dominant species in each $\mathrm{ESI}^{+}$and $\mathrm{ESI}^{-}$channel, but their molecular weight differ by $34 \mathrm{~g} / \mathrm{mole}$. Whether they are the same molecule or two distinct molecules will need further investigation. 


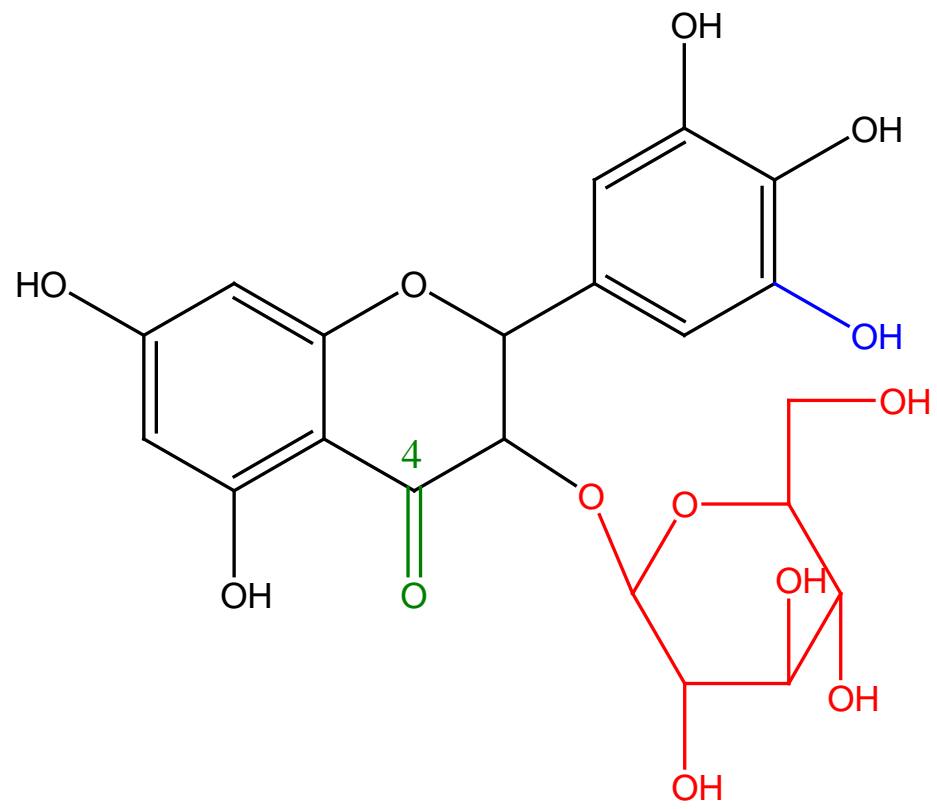

Fig. 8 Speculated molecule from known properties and depicted molecular weight indicated by LC-MS. The base molecule is an epigallocatechin gallate of molecular weight of 458 but substituting the gallate with a hexose, a glucose in this depicted molecule, and an oxidation on $\mathrm{C} 4$ position to a ketone moiety which brings the molecular weight to $482.11 \mathrm{~g} / \mathrm{mole}$, a perfect match to the anion spectra in Fig. 3.

Hypoglycemic phytochemical in guava leaf extract: Despite the fact that guava leaf extract possesses a hypoglycemic efficacy and the capacity to inactivate PTP1B enzyme activity, our future work still need to identify the phytochemical in the guava leaf that can contribute to the inactivation of PTP1B or even the hypoglycemic efficacy. We have found that the purification of aqueous partition difficult because of its oxidative reactivity. Nonetheless, the PTP1B inactivation property should contribute to the hypoglycemic efficacy associated with guava leaf extract as demonstrated in our study.

\section{Conclusions}

The guava leaf extract can modulate insulin activity through a redox regulation on PP1B enzymatic activity. The guava leaf tea can serve as a functional hypoglycemic drink that is suitable for either healthy or diabetic subjects.

\section{Acknowledgements}

The authors would express our sincere gratitude to Dr. Lie-Fen Shyur at the Agricultural Biotechnology
Research Center, Academia Sinica for helping out our phytochemical purification as well as special thanks to Chih-Yu Lin at the Metabolomics Core Facility of Agricultural Biotechnology Research Center, Academia Sinica for her service on LC-MS analysis. All authors have agreed to publish this manuscript and have no conflict of interest with this publication. The animal study was approved by the regulatory group at Academia Sinica before it was carried out.

Funding: This work was supported by Asia University grants [101-Asia-47], Asia University/China Medical University Hospital joint grant [ASIA-105-CMUH-21], and Asia University/Asia University Hospital/China Medical University Hospital grant [ASIA-106-CMUH-27].

\section{Author contributions}

W-J W and C-T C conducted PTP1B enzymatic assay;

W-L Y carried out CHO toxicity assay;

G G carried out glucose uptake assay;

S-C Y performed phenol, flavonoids, DPPH assay;

C-Y L C-Y H provided guava leaf for this study; 
H-W C, C-K L assisted the glucose uptake assay;

A L Y provided access to animal study;

C-C C and Y-T C were consulted for clinical application;

$\mathrm{H} \mathrm{J} \mathrm{T}$ is responsible for this project.

\section{References}

[1] Ezzati, M. et al. 2016. "Trends in Adult Body-Mass Index in 200 Countries from 1975 to 2014: A Pooled Analysis of 1698 Population-Based Measurement Studies with 19.2 Million Participants.” Lancet 387: 1377-96.

[2] Ross, S. A., Gulve, E. A., and Wang, M. 2004. "Chemistry and Biochemistry of Type 2 Diabetes.” Chem. Rev. 104: 1255-82.

[3] Nejentsev, S. et al. 2007. "Localization of Type 1 Diabetes Susceptibility to the MHC Class I Genes HLA-Band HLA-A.” Nature 450 (7171): 887-92.

[4] Gale, E. A. 2001. “The Discovery of Type 1 Diabetes.” Diabetes 50: 217-26.

[5] Lin, C. Y., and Yin, M. C. 2012. "Renal Protective Effects of Extracts From Guava Fruit (Psidium Guajava L.) in Diabetic Mice.” Plant Foods Hum Nutr. 67: 303-8.

[6] Mukhtar, H. M., Ansari, S. H., Ali, M., Naved, T., and Bhat, Z. A. 2004. "Effect of Water Extract of Psidium Guajava Leaves on Alloxan-Induced Diabetic Rats.” Pharmazie 59: 734-5.

[7] Shen, S. C., Cheng, F. C., and Wu, N. J. 2008. "Effect of Guava (Psidium Guajava Linn.) Leaf Soluble Solids on Glucose Metabolism in Type 2 Diabetic Rats.” Phytother Res. 22: 1458-64.

[8] Ojewole, J. A. 2005. "Hypoglycemic and Hypotensive Effects of Psidium Guajava Linn. (Myrtaceae) Leaf Aqueous Extract.” Methods Find Exp Clin Pharmacol 27: 689-95.

[9] Deguchi, Y, and Miyazaki, K. 2010. "Anti-Hyperglycemic and Anti-Hyperlipidemic Effects of Guava Leaf Extract.” Nutr Metab (Lond) 7: 9.

[10] Oh, W. K., Lee, C. H., Lee, M. S., Bae, E. Y., Sohn, C. B., Oh, H., Kim, B. Y., and Ahn, J. S. 2005. "Antidiabetic Effects of Extracts from Psidium Guajava.” $J$. Ethnopharmacol 96: 411-5.

[11] Guo, X., Yoshitomi, H., Gao, M., Qin, L., Duan, Y., Sun, W., Xu, T., Xie, P., Zhou, J., Huang, L., and Liu, T. 2013. "Guava Leaf Extracts Promote Glucose Metabolism in SHRSP.Z-Leprfa/Izm Rats by Improving Insulin Resistance in Skeletal Muscle.” BMC Complement Altern Med. 13: 52.

[12] Chandra, S., Khan, S., Avula, B., Lata, H., Yang, M. H., ElSohly, M. A., and Khan, I. A. 2014. "Assessment of Total Phenolic and Flavonoid Content, Antioxidant
Properties, and Yield of Aeroponically and Conventionally Grown Leafy Vegetables and Fruit Crops: A Comparative Study.” Evid Based Complement Alternat Med. 2014: 253875.

[13] Kedare, S. B., and Singh, R. P. 2011. "Genesis and Development of DPPH Method of Antioxidant Assay.” J. Food Sci Technol. 48 (4): 412-22.

[14] Tsai, H. J., and Chou, S. Y. 2009. "A Novel Hydroxyfuroic Acid Compound as an Insulin Receptor Activator-Structure and Activity Relationship of a Prenylindole Moiety to Insulin Receptor Activation.” J. Biomed Sci. 16: 68.

[15] Vishwanath, D., Srinivasan, H., Patil, M. S., Seetarama, S., Agrawal, S. K., Dixit, M. N., and Dhar, K. 2013. "Novel Method to Differentiate 3T3 L1 Cells in Vitro to Produce Highly Sensitive Adipocytes for a GLUT4 Mediated Glucose Uptake Using Fluorescent Glucose Analog.” $J$. Cell Commun Signal 7 (2): 129-40.

[16] Welte, S., Baringhaus, K. H., Schmider, W., Müller, G., Petry, S., Tennagels, N. 2005. "6,8-Difluoro-4-Methylumbiliferyl Phosphate: A Fluorogenic Substrate for Protein Tyrosine Phosphatases.” Anal Biochem. 338 (1): 32-8.

[17] Goldstein, B. J., Mahadev, K., and Wu, X. 2005. "Redox Paradox: Insulin Action Is Facilitated by Insulin-Stimulated Reactive Oxygen Species with Multiple Potential Signaling Targets.” Diabetes 54 (2): 311-21.

[18] Salmeen, A., Andersen, J. N., Myers, M. P., Meng, T. C., Hinks, J. A., Tonks, N. K., and Barford, D. 2003. "Redox Regulation of Protein Tyrosine Phosphatase 1B Involves a Sulphenyl-Amide Intermediate." Nature 423 (6941): 769-73.

[19] Lewis, S. M., Li, Y., Catalano, M. J., Laciak, A. R., Singh, H., Seiner, D. R., Reilly, T. J., Tanner, J. J., and Gates, K. S. 2015. "Inactivation of Protein Tyrosine Phosphatases By Dietary Isothiocyanates.” Bioorg Med Chem Lett. 25 (20): 4549-52.

[20] Elchebly, M., Payette, P., Michaliszyn, E., Cromlish, W., Collins, S., Loy, A. L., Normandin, D., Cheng, A., Himms-Hagen, J., Chan, C. C., Ramachandran, C., Gresser, M. J., Tremblay, M. L., and Kennedy, B. P. 1999. "Increased Insulin Sensitivity and Obesity Resistance in Mice Lacking the Protein Tyrosine Phosphatase-1B Gene.” Science 283 (5407): 1544-8.

[21] Johnson, T. O., Ermolieff, J., and Jirousek, M. R. 2002. "Protein Tyrosine Phosphatase 1B Inhibitors for Diabetes." Nat. Rev. Drug Discov. 1 (9): 696-709.

[22] Zhang, S., and Zhang, Z. Y. 2007. "PTP1B as a Drug Target: Recent Developments in PTP1B Inhibitor Discovery.” Drug Discov. Today 12 (9-10): 373-81. 
[23] Combs, A. P. 2010. "Recent Advances in the Discovery of Competitive Protein Tyrosine Phosphatase 1B Inhibitors for the Treatment of Diabetes, Obesity, and Cancer.” J. Med Chem. 53 (6): 2333-44.

[24] Iversen, L. F., Moller, K. B., Pedersen, A. K., Peters, G. H., Petersen, A. S., Andersen, H. S., Branner, S., Mortensen, S. B., and Moller, N. P. 2002. "Structure Determination of T Cell Protein-Tyrosine Phosphatase.” J. Biol Chem. 277 (22): 19982-90.

[25] Mahadev, K., Zilbering, A., Zhu, L., and Goldstein, B. J. 2001. "Insulin-Stimulated Hydrogen Peroxide Reversibly
Inhibits Protein-Tyrosine Phosphatase 1B in Vivo and Enhances the Early Insulin Action Cascade.” J. Biol Chem. 276 (24): 21938-42.

[26] Nakayama, T., Ichiba, M., Kuvabara, M., Kajiya, K., and Kumazawa, S. 2002. "Mechanisms and Structural Specificity of Hydrogen Peroxide Formation during Oxidation of Catechins.” Food Sci. Technology Res. 8 (3): 261-7.

[27] Ma, J., Li, Z., Xing, S., Ho, W. T., Fu, X., and Zhao, Z. J. 2011. "Tea Contains Potent Inhibitors of Tyrosine Phosphatase PTP1B." Biochem Biophys Res. Commun 407 (1): 98-102. 